23

\title{
О возможностях многомерной эквидистантной абсорбционной спектроскопии в широком диапазоне частот в исследованиях фракций термической разгонки нефти
}

\author{
() Н.И. Егорова ${ }^{1}$, И.О. Конюшенко ${ }^{2}$, В.М. Немец ${ }^{3,}$, С.А. Пеганов ${ }^{4}$ \\ ${ }^{1}$ Санкт-Петербургский университет ГПС МЧС России, \\ 196105 Санкт-Петербург, Россия \\ ${ }^{2} \mathrm{AO}$ „НПК-Пеленгатор“, \\ 198095 Санкт-Петербург, Россия \\ ${ }^{3}$ Санкт-Петербургский государственный университет, \\ 198504 Санкт-Петербург, Россия \\ ${ }^{4}$ ЗАО „НИИ проблем автоматизации „СеверЭВМкомплекс“, \\ 191119 Санкт-Петербург, Россия \\ ฯ e-mail: nemec_vm@mail.ru
}

Поступила в редакцию 13.11. 2019 г.

В окончательной редакции 24.12.2019 г.

Принята к публикации 26.12.2019 г.

\begin{abstract}
Исследованы особенности и возможности абсорбционной молекулярной спектроскопии сложных смесей органических соединений на примере фракций термической разгонки нефти. Образцы нефти отбирали из трубопровода, по которому нефть поступает от различных месторождений. С целью обеспечения независимого (относительно месторождения) отбора образцов нефти отбор осуществляли с интервалом в три месяца. Непосредственно решалась задача исследования спектров нефтяных фракций как единого целостного объекта (т. е. без исследования молекулярного состава) сложного молекулярного состава. В связи с этим обработке подвергались многомерные эквидистантные спектры в широком спектральном диапазоне. Условия измерений: диапазон частот от 500 до $1500 \mathrm{~cm}^{-1}$, спектральное разрешение $1 \mathrm{~cm}^{-1}$, шаг изменения частоты $0.5 \mathrm{~cm}^{-1}$. Исследуемые объекты -33 фракции термической разгонки нефти. Обработка результатов спектроскопических измерений проводилась с использованием методов многофакторной математической статистики. Показана эффективность использования абсорбционной молекулярной спектроскопии в средней ИК области в исследовании и контроле оптических характеристик (спектров поглощения) фракций термической разгонки нефти.
\end{abstract}

Ключевые слова: абсорбционная молекулярная спектроскопия, средняя ИК область, фракции термической разгонки нефти, многомерные эквидистантные спектры, метод главных компонент, информационная способность спектров.

DOI: $10.21883 /$ OS.2020.04.49208.309-19

\section{Введение}

Абсорбционно-спектроскопические измерения являются в настоящее время одним из наиболее распространенных элементов решения различных задач нефтепереработки и нефтехимии. При этом возможны исследования как чистых объектов, так и нефтепродуктов сложного молекулярного состава. Основные решаемые задачи, как правило, включают обнаружение, классификацию или идентификацию отдельных молекулярных компонентов, оценку их концентраций или же установление их структуры. Такие задачи решаются на основе измерений поглощения на одной или нескольких характеристических частотах в узком спектральном интервале характерного поглощения исследуемой молекулярной формы, выделяемом спектральной системой. Такой подход позволяет использовать абсорбционную спектроскопию в целях, например, определения концентрации заданного молекулярного компонента. По результатам определе- ния концентраций нескольких характерных компонентов возможна классификация или идентификация объекта в целом [1-8]. Однако такой путь решения может быть сложным, недешевым в методическом и аппаратурном обеспечении, трудоемким и длительным при реализации и неприменим в рабочей зоне с целью экспресс-контроля параметров того или иного технологического процесca $[7,8]$.

Говоря о возможностях классификации или идентификации объекта сложного молекулярного состава, можно предполагать, что решение этой задачи более удобно и эффективно может быть получено на основе многомерной абсорбционной спектроскопии в широком диапазоне частот с использованием измерений поглощения в эквидистантно расположенных точках спектра $[9,10]$. При таком подходе информационные возможности абсорбционной спектроскопии должны быть значительно выше, поскольку число эквидистантно расположенных точек в широком спектральном интервале может быть 
несоизмеримо более высоким. В связи с этим настоящая работа исследует информационную возможность (характеризуемую коэффициентом К сти для $k$ главных компонент [11]) многомерной абсорбционной спектроскопии фракций термической разгонки нефти с использованием эквидистантных спектров в широком диапазоне частот.

\section{1. Теория}

Теоретическое обеспечение работы заключалось, вопервых, в применении метода главных компонент (МГК) [12,13] для обработки результатов измерения спектров фракций термической разгонки нефти, вовторых, в применении математических моделей построения синтезированных спектров компаундов нефтяных фракций и их обработки.

\section{2. Эксперимент и его результаты}

\section{1. Объекты исследований}

Исследовали два независимо отобранных образца нефти (условно „первый“ и „второй“汭. Отобранные образцы нефти подвергли термической разгонке (условно „разгонка 1“ и „разгонка 2“) на аппарате АРН-2 по ГОСТ 110-11-85 с температурным шагом отбора фракций, равным $10^{\circ} \mathrm{C}$. В итоге получили две разгонки по 33 фракции.

\section{2. Техника и условия спектроскопических измерений}

Спектры оптической плотности нефтяных фракций и их компаундов измеряли в диапазоне частот от 500 до $1500 \mathrm{~cm}^{-1}$ со спектральным разрешением $1 \mathrm{~cm}^{-1}$ и шагом изменения частоты $0.5 \mathrm{~cm}^{-1}$ на спектрометре „Bruker6 в средней ИК области. Измерения в диапазоне 320-2500 nm в ближней ИК и видимой областях на спектрофотометре Varian Cary 5000 (спектральное разрешение и шаг измерения $1 \mathrm{~nm})$.

Исследуемые образцы фракций вводили в кювету из $\mathrm{NaCl}$ с толщиной поглощающего слоя $200 \mu \mathrm{m}$. Измерения проводили при температуре $20 \pm 1^{\circ} \mathrm{C}$. Образцы фракций хранили в холодильнике, что приводило к формированию твердой фазы в тяжелых фракциях. Перед измерениями пробы фракций прогревали при температуре $20^{\circ} \mathrm{C}$ до их полной гомогенизации.

\section{3. Предварительная обработка спектров}

Исследования показали, что наиболее информативны измерения при следующей обработке спектров.

Исключали из обработки части спектра, в которых значения оптической плотности достигают или превышают единичное значение. Это позволило исключить области с высоким уровнем шумов.
Таблица 1. Рассчитанные значения коэффициента информационности для главных компонент термических разгонок двух независимо отобранных образцов нефти

\begin{tabular}{c|c|c|c}
\hline \multicolumn{2}{c|}{ Первая разгонка } & \multicolumn{2}{c}{ Вторая разгонка } \\
\hline Номер ГК & К $_{\text {инф }} \%$ & Номер ГК & Кинф, $\%$ \\
\hline 1 & 54 & 1 & 47 \\
2 & 21 & 2 & 26 \\
3 & 9 & 3 & 12 \\
4 & 6 & 4 & 7 \\
5 & 4 & 5 & 4
\end{tabular}

В исходных спектрах в областях, достаточно далеко отстоящих друг от друга и в наибольшей степени свободных от полос поглощения, проводили базовую линию, от которой заново отсчитывали значения интенсивностей полос спектра. Как видно из рис. 1, такими являются область среднего ИК диапазона, около $500 \mathrm{~cm}^{-1}$, и область около $3100 \mathrm{~cm}^{-1}$. Таким образом, приводили базовые линии всех спектров к нулевому уровню.

Сглаживали спектр с целью удаления шума - как спектрального, так и измерительной системы. Для сглаживания спектра применяли метод СавицкогоГолея [14]. Параметры используемого метода (диапазон и порядок полинома) выбирали исходя из значений ширин спектральных полос и шумовых особенностей. Наиболее адекватными параметрами для нашего случая являются 9 для диапазона и 2 для степени полинома.

Использовали производную по длине волны предварительно обработанного спектра. Дифференцирование спектра осуществляли в связи с тем, что информация содержится не столько в абсолютных значениях поглощения, сколько в профиле формы его зависимости от длины волны (форма функции лучше всего описывается значениями ее производной) [15].

На каждом этапе процедуры обработки проводили исследование результата на предмет соответствия указанному выше критерию непрерывности и гладкости.

В итоге в пространстве главных компонентов формировали более или менее гладкую непрерывную кривую, соответствующую группе фракций, полученных при термической разгонке нефти. Это свидетельствует о корректности проведенной предварительной обработки спектров фракций.

\section{4. Совместная обработка спектров фракций двух разгонок и отображение их проекций на единой статистической плоскости}

Расчет системы главных компонентов (ГК) для спектров фракций исследуемых разгонок

В табл. 1 представлены результаты расчета значений коэффициента $\mathrm{K}_{\mathrm{OИ}}$ для ГК первой и второй разгонок образцов нефти. Как следует из табл. 1, в первой разгонке первые пять ГК содержат 94\% информации, 


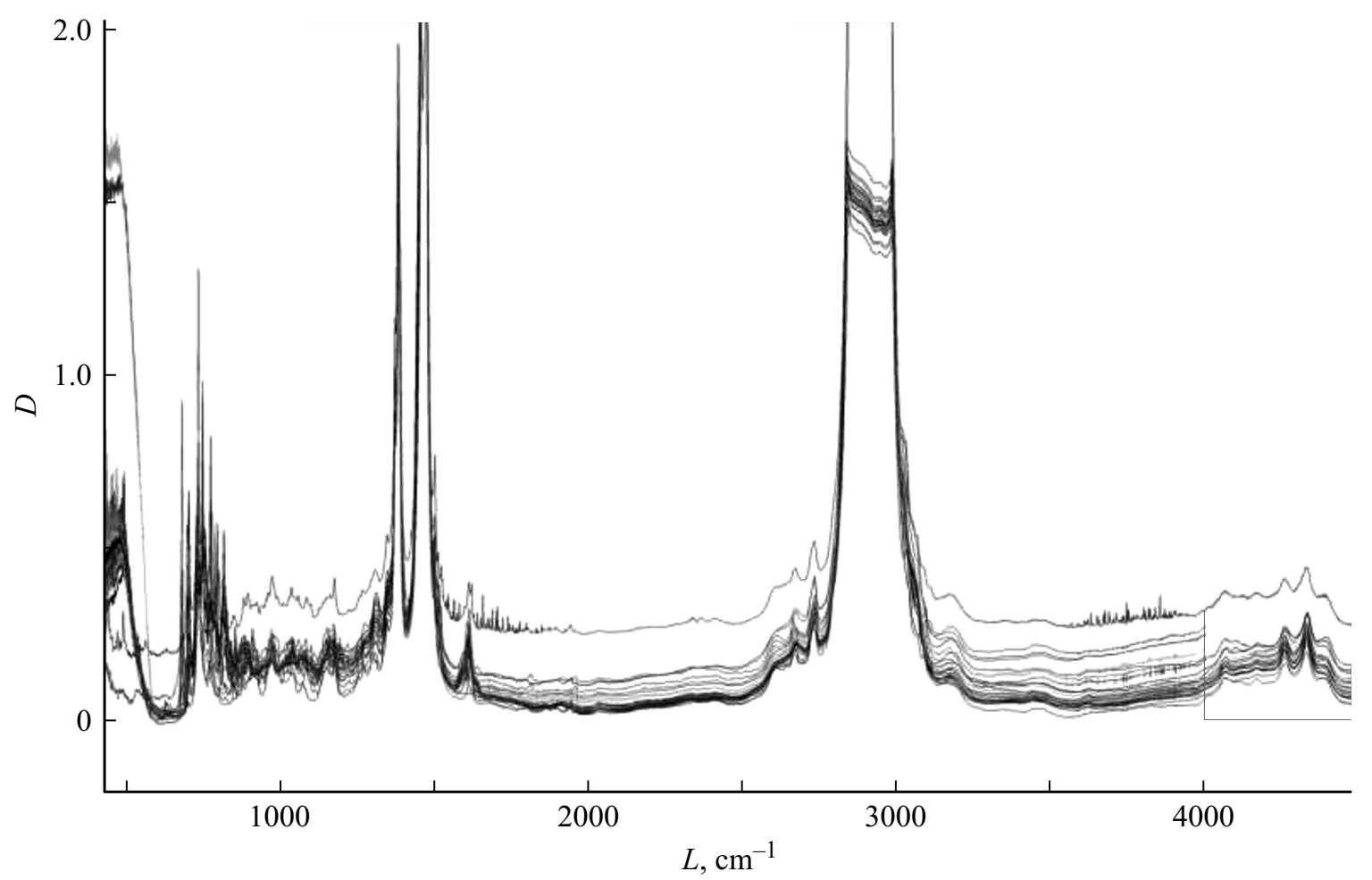

Pис. 1. Спектры оптической плотности $\mathrm{D}$ нефтяных фракций в средней ИК области.

информационность первых пяти ГК второй разгонки составляет $96 \%$.

\section{Сопоставление двух систем ГК}

Поскольку ГК - базисные векторы системы координат, можно решить вопрос о том, насколько близки направления, задаваемые ГК одних и тех же номеров фракций двух систем - первой и второй разгонки. Это позволит понять, насколько однородны различия между фракциями в разгонках и как велико влияние изменения состава нефти. Наиболее простой способ оценить близость направлений - рассчитать угол между базисными векторами с использованием скалярного произведения:

$$
\cos \varphi=\frac{(\mathbf{a}, \mathbf{b})}{|\mathbf{a}||\mathbf{b}|}
$$

где $\mathbf{a}$ и $\mathbf{b}-$ векторы. Учитывая, что базисные векторы нормированы, косинус угла между ними равен значению скалярного произведения. Соответствующие значения составляют для первых ГК - 0.986, для вторых ГК -0.985 , для третьих ГК -0.852 , для четвертых ГК -0.877 , для пятых ГК - 0.953. Эти значения указывают на то, что системы ГК, рассчитанные отдельно для каждого из двух семейств спектров, соответствующих различным разгонкам, близки между собой, однако не идентичны. Их различие может быть обусловлено влиянием различий составов нефти, использовавшихся в двух разгонках. Наибольшие различия наблюдаются между третьими и четвертыми компонентами, в то время как первые и вторые практически идентичны (в пределах статистической погрешности). Это обстоятельство говорит о том, что основные различия между разгонками лежат в области тяжелых фракций (начиная с $\left.200-210^{\circ} \mathrm{C}\right)$ и определяются либо различием состава нефти, либо нестабильностью процедуры разгонки.

\section{Построение проекций спектров двух разгонок в единой системе ГК}

Для сопоставления кривых, образуемых проекциями спектров каждой из двух разгонок, они должны быть построены в единой системе ГК. Поскольку базисные векторы двух независимых систем ГК, рассчитанные по каждой разгонке отдельно, довольно близки (см. выше), можно выбрать в качестве общей одну из индивидуальных систем ГК. В принципе при построении единой базы для определения того или иного характеристического свойства или идентификации фракций в качестве общей системы следует использовать усредненную, рассчитанную в виде суперпозиции индивидуальных систем. На рис. 2, $a$ показаны проекции спектров фракций двух разгонок на оси общей системы первых двух ГК (ГК и $\left.\Gamma_{2}\right)$, в качестве которой выбрана система первой разгонки. По осям РC1, РC2 и РС3 показаны значения координат проекций спектров фракций термической разгонки образцов нефти на статистической плоскости. Отметим, что эта картина представляет интерес до границы тяжелых фракций $\left(220-230^{\circ} \mathrm{C}\right)$. Область тяжелых фракций более адекватно отображается на плоскости 

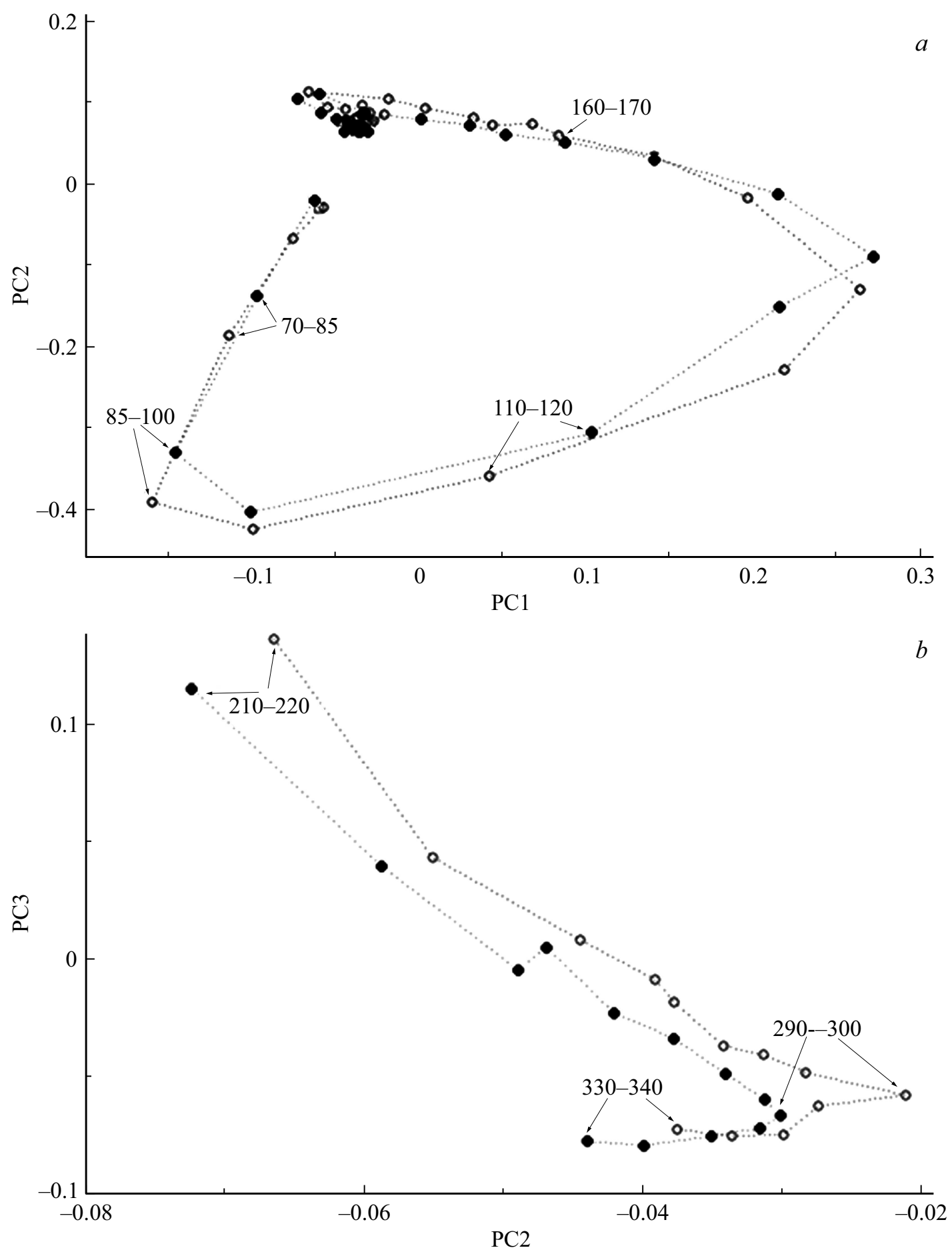

Рис. 2. Проекции спектров фракций двух разгонок на оси общей системы первых двух главных компонент ГК 1 (РС1) и ГК 2 (РС2) в качестве которой выбрана система первой разгонки: $a-$ полный набор фракций - РC1 и РС2, $b-$ область тяжелых фракций PC2 и РС3. Пояснения в тексте.

проекций на вторую и третью ГК, как это следует из рис. $2, b$. Из рассмотрения рис. $2, a$ и $2, b$ можно сделать следующие выводы.

Во-первых, кривые на рис. 2, $a$ до границы тяжелых фракций довольно близки между собой. При этом если полагать, что пространственное положение кривых опре- деляется составом нефти, то близость кривых соответствует близости составов образцов нефти, используемых для разгонки.

Во-вторых, расхождение положения точек на кривых может определяться различными факторами, в том числе погрешностями установления температуры термоста- 
Таблица 2. Результаты тестирования нейронной сети (идентификация температуры кипения фракций)

\begin{tabular}{c|c|c|c}
\hline $\begin{array}{c}\text { Номер } \\
\text { фракции }\end{array}$ & $\begin{array}{c}\text { Диапазон } \\
\text { температур } \\
\text { выкипания } \\
\text { фракций, } \\
{ }^{\circ} \text { С }\end{array}$ & $\begin{array}{c}\text { Тестирование } \\
\text { нейронной } \\
\text { сети, } \\
{ }^{\circ} \text { C }\end{array}$ & $\begin{array}{c}\text { Результат } \\
\text { иденти- } \\
\text { фикаци, } \\
{ }^{\circ} \text { С }\end{array}$ \\
\hline 1 & нк-62 & 65 & 65 \\
2 & $62-70$ & 67 & 68 \\
3 & $70-85$ & 85 & 85 \\
4 & $85-100$ & 101 & 105 \\
5 & $100-110$ & 109 & 110 \\
6 & $110-120$ & 120 & 120 \\
7 & $120-130$ & 131 & 130 \\
8 & $130-140$ & 137 & 135 \\
9 & $140-150$ & 150 & 150 \\
10 & $150-160$ & 163 & 163 \\
11 & $160-170$ & 173 & 173 \\
12 & $170-180$ & 180 & 178 \\
13 & $180-190$ & 186 & 184 \\
14 & $190-200$ & 198 & 190 \\
15 & $200-210$ & 203 & 200 \\
16 & $210-220$ & 212 & 210 \\
17 & $220-230$ & 228 & 226
\end{tabular}

тирования кипении фракций и возможным взаимодействием компонентов нефти.

B-третьих, наблюдаемые некоторые особенности во взаимном расположении точек на кривых, в частности, до фракции $160-170^{\circ} \mathrm{C}$ (за исключением фракции от начала кипения до $62^{\circ} \mathrm{C}$ (нк-62 ${ }^{\circ} \mathrm{C}$ ) точки, соответствующие одинаковым фракциям, наиболее близки между собой. После этой фракции наблюдается некий сдвиг: фракция $170-180^{\circ} \mathrm{C}$ второй разгонки ближе всего к фракции $180-190^{\circ} \mathrm{C}$ первой разгонки, фракция $180-190^{\circ} \mathrm{C}$ второй разгонки ближе всего к фракции $190-200^{\circ} \mathrm{C}-$ первой разгонки и так далее до границы тяжелых фракций.

В-четвертых, из рис. $2, b$ видно, что, начиная с фракции $210-220^{\circ} \mathrm{C}$, соответствующие участки кривых и точки на них вновь выравниваются с тем, чтобы дальше разойтись вновь.

\section{О возможности построения обучаемой процеду- ры идентификации фракций}

В развитие вышеизложенных результатов в работе сделана попытка использования спектров для иллюстрации возможности построения обучаемой процедуры идентификации фракций и определения температур их выкипания. Такая процедура построена на основе нейронной сети радиального базиса. Выбор именно этого типа сети обусловлен ее приспособленностью для аппроксимации функциональных зависимостей, каковой и является многомерная кривая, образуемая проекциями спектров фракций на ГК многомерной системы коор- динат. Использование нейронной сети в идентификации температур фракций позволяет получить количественную оценку возможностей заявляемого способа. В эксперименте в качестве характеристических свойств фракций рассматривались значения верхних температур выкипания фракций. При этом использовали три разгонки нефти. Из них две разгонки (первую и вторую) провели для двух образцов одной и той же нефти. В третьей разгонке использовали независимо отобранный образец нефти. Обучение сети проводили по проекциям спектров третьей разгонки на первые пять ГК первой разгонки. Для тестирования степени обученности системы использовали проекции спектров фракций второй разгонки. Для идентификации температур кипения фракций („рабочий“ цикл) использовали проекции спектров первой разгонки. Результаты приведены в табл. 2. Из нее видно, что отклонение значения идентифицируемой температуры от соответствующего значения результата тестирования системы не превышает $25-30 \%$ от используемого шага изменения температуры при переходе от одной фракции к соседней. Приведенные в таблице данные подтверждают работоспособность нейронной сети в выбранной конфигурации и возможность использования молекулярной абсорбционной спектроскопии для идентификации температур выкипания нефтяных фракций и тем самым для идентификации фракций. Наблюдаемое отсутствие абсолютной точности воспроизведения температур обучающего набора (тестирование) иллюстрирует сложность аппроксимации кривой распределения проекций спектров фракций на статистической плоскости, наличие на ней пока не объясненных особенностей. Кроме того, следует принять во внимание, что обучающий и тестирующий наборы спектров принадлежат фракциям, температурные границы которых не являются точно определенными.

\section{5. Синтез спектров компаундов нефтяных фракций. Возможности прогнозирования спектров компаундов}

Прогностические возможности характеристических спектров компаундов при их формировании определяются прежде всего тем, насколько аддитивны их абсорбционные спектры. Сама по себе проблема аддитивности светопоглощения смеси сложного молекулярного состава активно изучается [16-20]. К настоящему моменту достоверно выявлено наличие отклонения от аддитивности светопоглощения в некоторых частных случаях, связанных с количественными аналитическими измерениями (как правило, нефтепродукты, содержащие различного рода присадки). Тем не менее на настоящий момент времени каких-либо регламентирующих документов по необходимости учета неаддитивности светопоглощения при разработках новых спектрофотометрических методик измерений состава не существует. В связи с этим в настоящей работе проведена экспериментальная проверка значимости неаддитивности светопоглощения при 


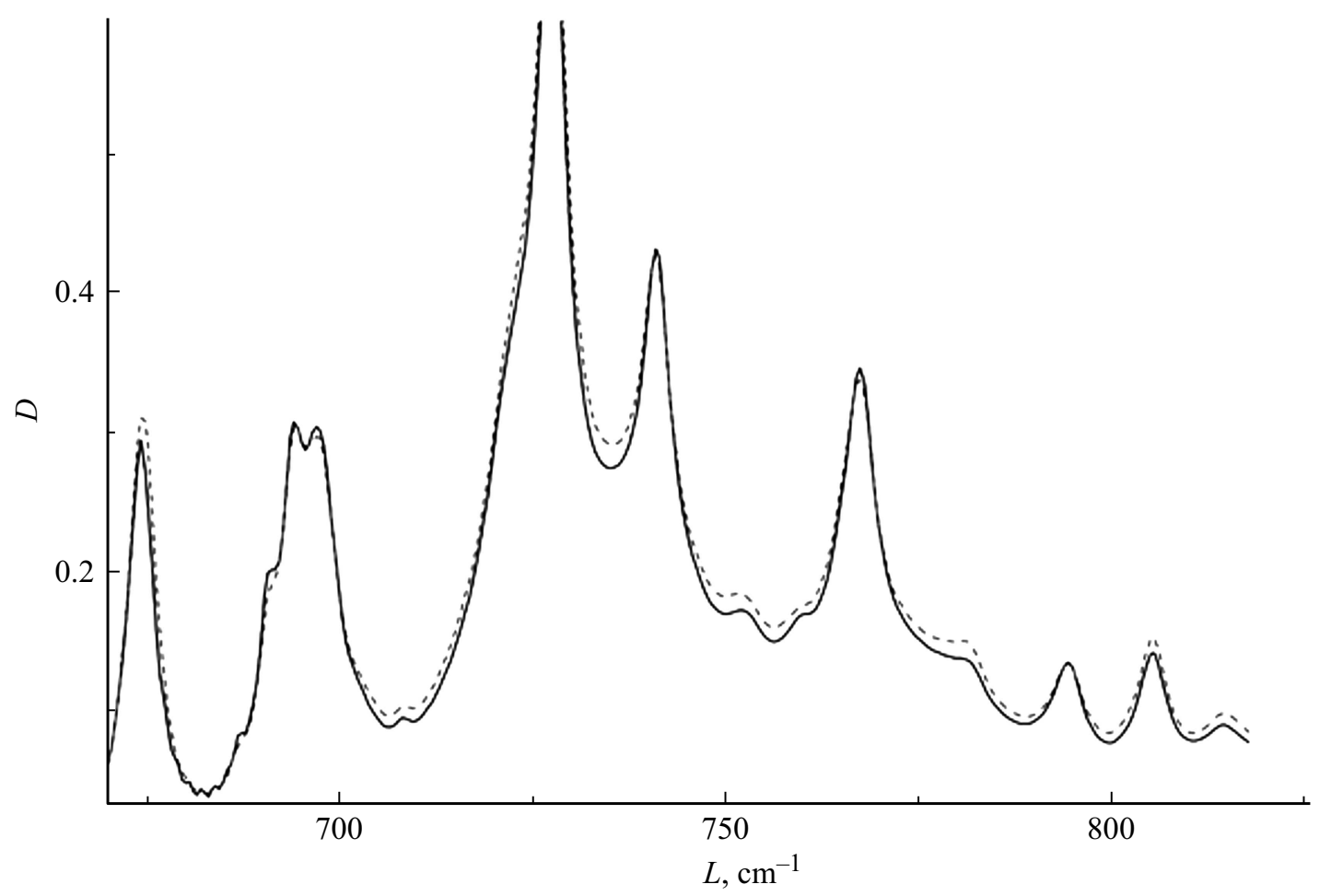

Рис. 3. Реальный (сплошная кривая) и синтезированный (штрихи) спектры компаунда нк- $180^{\circ} \mathrm{C}$ первой разгонки.

исследовании спектров компаундов нефтяных фракций. С этой целью исследована сходимость расчетных („синтезированных“) спектров компаундов нефтяных фракций с их реальными спектрами.

Исследованы вероятная неаддитивность поглощения компаундов в средней и ближней ИК областях, а также возможность прогнозирования характеристических спектров компаундов по спектрам фракций нефти, их составляющих.

\section{Расчет синтезированных спектров}

Расчет синтезированных спектров проводили на базе данных о выходе фракций на скорректированную нагрузку. Расчетные формулы для ГК синтезированных спектров имеют вид

$$
\begin{array}{r}
P 1_{S}=\frac{\sum_{i} P 1_{i} C_{i}}{\sum_{i} C_{i}}, \\
P 2_{S}=\frac{\sum_{i} P 2_{i} C_{i}}{\sum_{i} C_{i}}, \\
\\
P N_{S}=\frac{\sum_{i} P N_{i} C_{i}}{\sum_{i} C_{i}} .
\end{array}
$$

Здесь $P 1_{S} \ldots P N_{s}-$ ГК синтезированного спектра ( $N$ компонент), $P 1_{i} \ldots P N_{i}-$ ГК для спектра $i$-й фракции ( $N$ компонент), $C_{i}-$ выход $i$-й фракции на нагрузку. Суммирование проводили по фракциям, составляющим компаунд.
При синтезе спектра в исходном пространстве расчетная формула выглядит иначе:

$$
D_{S}\left(\lambda_{k}\right)=\frac{\sum_{i} D_{i}\left(\lambda_{k}\right) C_{i}}{\sum_{i} C_{i}}
$$

Здесь $D_{S}\left(\lambda_{k}\right)-$ синтезированная оптическая плотность на длине волны $\lambda_{k}, D_{i}\left(\lambda_{k}\right)$ - оптическая плотность $i$-й фракции на длине волны $\lambda_{k}$.

\section{Результаты синтеза спектров}

Результаты синтеза спектра компаунда нк- $180^{\circ} \mathrm{C}$ первой разгонки в исходном пространстве приведены на рис. 3 штрихами. На этом же рисунке сплошной линией показан натуральный спектр компаунда нк- $180^{\circ} \mathrm{C}$. Приведен участок спектра, так как на общем виде спектра различия практически незаметны в используемом на рисунке масштабе. Визуально синтезированные и реальные спектры компаундов довольно близки. Аналогичный результат получен при исследовании других компаундов, например, $110-325^{\circ} \mathrm{C}$ и $110-250^{\circ} \mathrm{C}$ первой разгонки, нк- $180^{\circ} \mathrm{C}$ - второй разгонки.

На рис. 4, $a$ показаны результаты расчета синтезированных спектров и отображения исходных спектров в пространстве первых двух ГК для компаунда нк- $180^{\circ} \mathrm{C}$ первой разгонки (nk180sint - синтезированный и nk180real - реальный). Наглядно проявляется природа образцов как компаундов соответствующих фракций: отображающие спектры (синтезированный и реальный) фракций лежат в центре области, описанной 

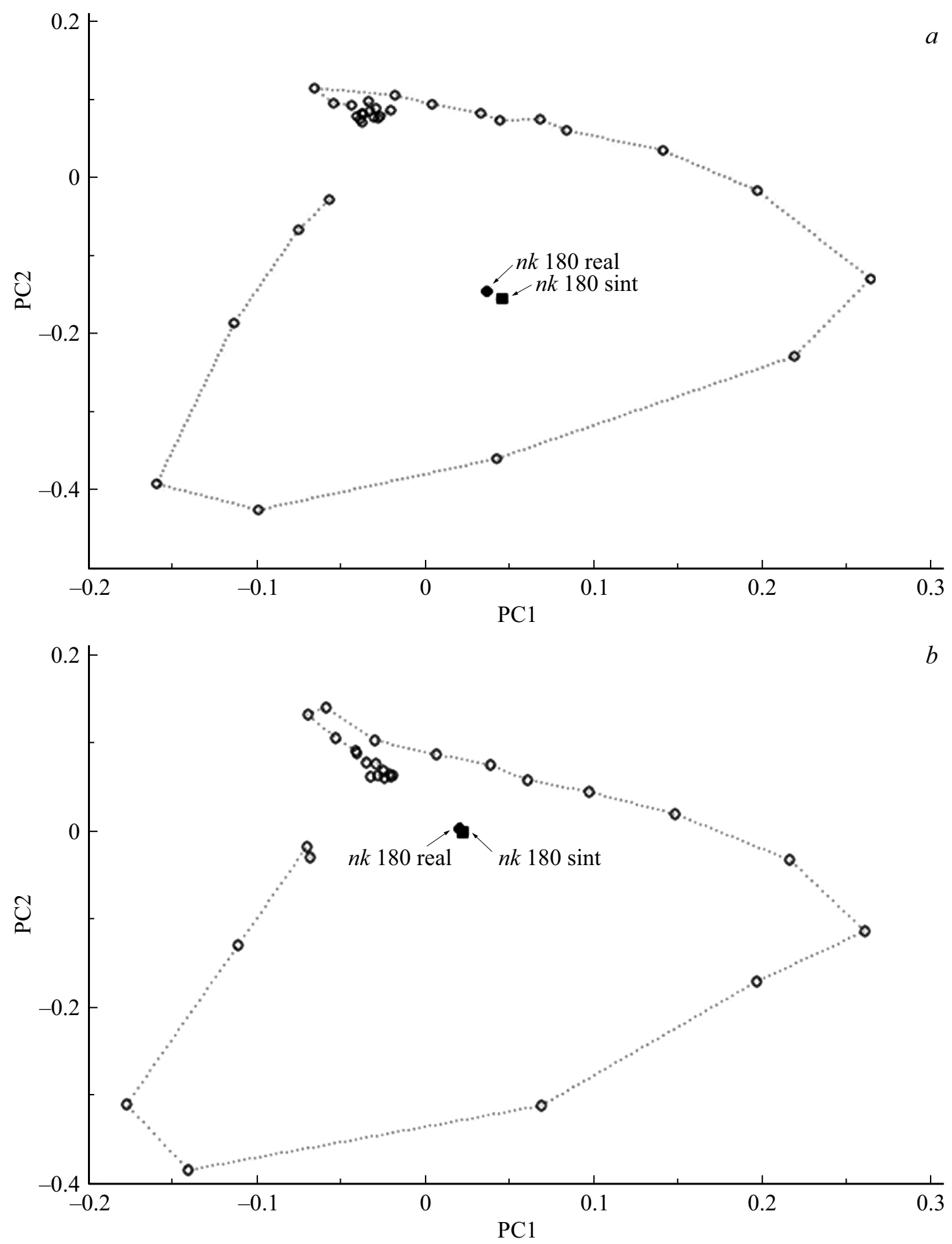

Рис. 4. Проекции спектров на единую плоскость двух первых ГК (РС1, РС2): $a$ - первая разгонка: • - реальные для смеси nk180 real, - - синтезированные, о - реальные для фракций; $b-$ вторая разгонка: обозначения те же.

вокруг точек-изображений спектров исходных фракций с учетом весов - концентраций фракций в компаунде. Из рис. 4, $a$ видно, что разность между синтезированным и реальным спектрами меньше или сравнима с расстояниями между фракциями, составляющими компаунд на плоскости двух первых ГК. В табл. 3 приведе- ны рассчитанные значения расстояний Эвклида между синтезированным и реальным спектрами компаундов в пространстве шести ГК.

Для смеси нк- $180^{\circ} \mathrm{C}$ второй разгонки взаимное расположение изображений фракций синтезированного и реального спектров приведено на рис. $4, b$. Точки, соот- 


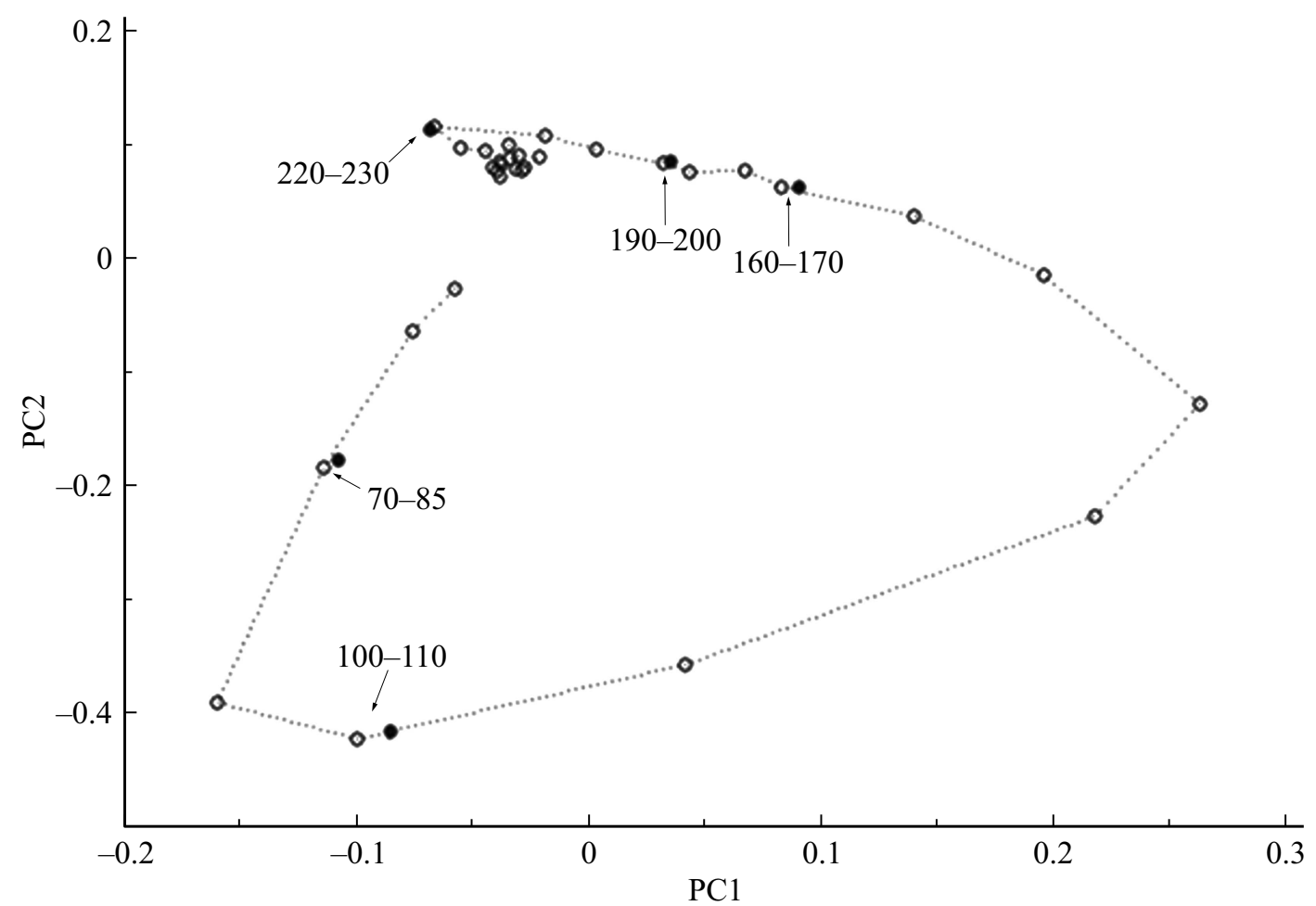

Рис. 5. Исследование влияния временного фактора на распределение проекций спектров фракций первой разгонки в плоскости двух первых ГК (РС1, РС2). Пояснения в тексте.

Таблица 3. Расстояние Эвклида между синтезируемым и реальным спектрами компаундов в пространстве шести главных компонент

\begin{tabular}{|c|c|}
\hline Компаунд „нк- $180^{\circ} \mathrm{C}^{\text {“ }}$ & 0.0167 \\
\hline Компаунд „110-250 ${ }^{\circ} \mathrm{C}^{\text {“ }}$ & 0.0125 \\
\hline Компаунд „110-325 $\mathrm{C}^{\circ}$ & 0.0154 \\
\hline $\begin{array}{l}\text { Экспериментальный разброс } \\
\text { (компаунд „100-110 } \mathrm{C}^{\star} \text { ) }\end{array}$ & 0.0198 \\
\hline
\end{tabular}

ветствующие реальному и синтезированному спектрам, практически сливаются. Некоторое тяготение смеси к тяжелым фракциям по сравнению с рис. 4, $a$ объясняется тем, что смесь нк- $180^{\circ} \mathrm{C}$ второй разгонки получали при смешивании фракций в равных количествах, тогда как для этой смеси первой разгонки соблюдалась пропорциональность по выходу на скорректированную нагрузку.

Приведенные результаты показывают, что в пределах случайной погрешности измерений можно говорить об идентичности синтезированного и реального спектров компаундов. Влияние межмолекулярных взаимодействий при компаундировании и других факторов, способных привести к значимым различиям в спектрах, имеет меньший масштаб, нежели случайные различия в составах отдельных фракций. Таким образом, реальна возможность формирования априорного представления о спектрах компаундов при наличии спектров составляющих их фракций. На этой основе, по-видимому, возможно и решение задачи получения априорных оценок других физических или физико-химических характеристических свойств компаундов.

Полученный результат, кроме того, свидетельствует об отсутствии значительного влияния межмолекулярного взаимодействия при компаундировании компонентов, входящих в состав нефти.

\section{6. Оценка временного изменения состава фракций термической разгонки нефти по их спектрам поглощения}

При проведении спектроскопических исследований нефтяных фракций значительную проблему могут вызвать изменения их состава во времени. Ввиду длительности процесса температурной разгонки, транспортировки и самого процесса измерений следует предполагать, что результаты измерений могут отражать влияние таких изменений. Поскольку механизмы, позволяющие сократить время разгонки, по-видимому, отсутствуют, полезно исследовать влияние временного фактора с целью определения возможности его учета.

Для решения этой задачи измерили спектры в следующем наборе фракций: $70-85^{\circ} \mathrm{C}, 100-110^{\circ} \mathrm{C}, 160-170^{\circ} \mathrm{C}$, $190-200^{\circ} \mathrm{C}$ и $220-230^{\circ} \mathrm{C}$ первой разгонки. Временной интервал между первоначальными измерениями и повторными составил 11 месяцев. На рис. 5 сопоставлены 
результаты таких измерений. Из рис. 5 видно, что временные изменения между первым (о) и вторым (•) измерениями существенно меньше, чем различия между фракциями. Полученный результат может иметь следующее объяснение. Скорость изменения состава и, следовательно, свойств фракций носит экспоненциальный характер: она максимальна сразу после разгонки и спадает во времени. Ввиду того, что между разгонкой и первоначальным измерением спектров проходит некоторое время, длительность которого обусловлена многими факторами, в том числе и неустранимыми особенностями технологии разгонки, можно предположить, что наибольшие изменения состава и, следовательно, спектров происходит еще до первоначального измерения. Малость изменений за 11-месячный промежуток может быть обусловлена именно этим. Полагая первоначальные изменения состава (в процессе и сразу после разгонки) неустранимыми, можно считать, что дальнейшие изменения состава уже незначительны (фракции лишились легколетучих компонентов). Поэтому существенные изменения результатов измерений не наблюдаются.

\section{7. Измерения в видимой и ближней ИК областях спектра}

Исследования показали, что, как и в случае измерений в средней ИК области, в ближней ИК области спектра прогнозирование оптических характеристик компаундов нефтяных фракций может быть также успешно выполнено. Алгоритм прогнозирования, результаты и выводы полностью аналогичны рассмотренным для случая средней ИК области.

\section{Благодарности}

Исследования проведены с использованием оборудования ресурсного центра Научного парка СПбГУ Геомодель.

\section{Конфликт интересов}

Авторы заявляют, что у них нет конфликта интересов.

\section{Список литературы}

[1] Глебовская E.A. Применение инфракрасной спектрометрии в нефтяной геохимии. Л.: Недра, 1971. $140 \mathrm{c}$.

[2] Батуева И.Ю., Гайле А.А., Поконова Ю.В. и др. Химия нефти. Л.: Химия, 1984. 343 с.

[3] Современные методы анализа нефтей (справочнометодическое пособие) / Под ред. Богомолова А.И., Темянко М.Б., Хотынцевой Л.И.. Л.: Недра, 1984. 431 с.

[4] Speight J.G. Handbook of Petroleum Analysis. NY.: John Wiley, 2001. 489 р. Перевод: Спейт Д.Г. Анализ нефти. Справочник. СПб.: Профессия, 2010. 479 с.

[5] Занозина И.И. // Нефтепереработка и нефтехимия. 2006. № 12. C. 21.
[6] Иванова Л.В., Сафиева Р.З., Кочелев В.Н. // Вестн. Башкирского ун-та. 2008. Т. 13. № 4. С. 869.

[7] Balabin R.M., Safieva R.Z., Lomakina E.J. // Anal. Chim. Acta. 2010. V. 671. N 1-2. P. 27.

[8] Бровко Е.А., Пурэвсурэн С., Сафиева Р.З., Сюняев Р.З., Чулюков О.Г., Жаринов К.А., Крашенинников А.А. // Нефтепереработка и нефтехимия. 2004. № 1. С. 36.

[9] Борисов В.Б., Немеи В.М., Полянский М.Н., Соловьев А.А. // Аналитика и контроль. 2000. Т. 4. № 2. С. 151.

[10] Берцев В.В., Борисов В.Б., Немец В.М., Сквориов Д.С., Соловьев В.A. // Заводская лаборатория. Диагностика материалов. 2002. Т. 68. № 12. С. 12.

[11] Айвазян С.А., Бухштабер В.М., Енюков И.С., Мешалкин Л.Д. Прикладная статистика. Классификация и снижение размерности. Справочное издание. М.: Финансы и статистика, 1989. $607 \mathrm{c}$.

[12] Дронов C.B. Многомерный статистический анализ. Учебное пособие. Барнаул: Алтайский госуниверситет, 2003. $213 \mathrm{c}$

[13] Эсбенсен К. Анализ многомерных данных. Избранные главы. Черноголовка: Изд-во ИПФХ РАН, 2005. 160 с.

[14] Savitzky A., Golay M.J.E. // Anal. Chem. 1964. V. 36. N 8. P. 1627.

[15] Дубровкин И.М. // ЖПС. 1983. Т. 39. В. 6. С. 885-898.

[16] Osterkamp D.L., Vinylogais Imides I. // J. Org. Chem. 1970. V. 35. N 5. P. $1632-1641$.

[17] Вершинин В.И., Цюпко Т.Г., Власова И.В. // Методы и объекты химического анализа. 2010. Т. 5. № 4. С. 226-234.

[18] Власова И.В., Шелпакова А.С., Добровольский С.М., Фисенко А.В. // Аналитика и контроль. 2009. Т. 13. № 3. C. $153-157$.

[19] Усова С.В., Богеза Ю.П., Гончаров Д.С., Вершинин В.И. // Аналитика и контроль. 2011. Т. 15. № 1. С. 78-86.

[20] Веснин В.Л., Мурадов В.Г. // Изв. Самарского научного центра РАН. 2013. Т. 15. № 6. С. 77-81. 